\title{
Elevated HABPI protein expression correlates with progression and poor survival in patients with gastric cancer
}

This article was published in the following Dove Press journal:

OncoTargets and Therapy

31 October 2016

Number of times this article has been viewed

\author{
Hongyu Gao' \\ Qiang Yao' \\ Xiuwen Lan' \\ Sen $\mathrm{Li}^{\prime}$ \\ Junlong $\mathrm{Wu}^{2}$ \\ Guangchun Zeng² \\ Yingwei Xue'
}

'Department of Gastroenterologic Surgery, ${ }^{2}$ Department of Pathology,

The Affiliated Tumor Hospital, Harbin Medical University, Harbin, People's Republic of China
Correspondence: Yingwei Xue Department of Gastroenterologic Surgery, The Affiliated Tumor Hospital, Harbin Medical University, 150 Haping Road, Harbin I5008I, People's Republic of China

Tel/fax +86 45I 86298303

Email xyw_801@।63.com
Background: Hyaluronic acid-binding protein $1(\mathrm{HABP} 1 / \mathrm{gC} 1 \mathrm{qR} / \mathrm{p} 32)$ has been recently implicated in oncogenesis and cancer progression in various malignancies; however, its clinical role in gastric cancer (GC) is still unclear.

Patients and methods: First, HABP1 expression was determined by Western blot analysis and immunohistochemistry. Then, we evaluated the expression of HABP1 and its clinical significance in tumor tissues from 181 patients with GC.

Results: Expression of HABP1 protein in GC tissues was noticeably higher than that in adjacent nonneoplastic tissues $(P=0.018)$. Increased HABP1 expression was significantly associated with tumor, node, and metastasis (TNM) stage $(P=0.006)$, depth of invasion $(P=0.001)$, lymph node metastasis $(P=0.001)$, liver metastasis $(P=0.024)$, and peritoneum metastasis $(P=0.009)$. Patients with high expression of HABP1 had poor overall survival rate $(P<0.001)$. In addition, histologic grade $(P=0.017)$, TNM stage $(P<0.001)$, Borrmann grouping $(P<0.001)$, depth of invasion $(P<0.001)$, lymph node metastasis $(P<0.001)$, liver metastasis $(P=0.010)$, and tumor size $(P<0.001)$ were independent prognostic factors for overall survival. Multivariate Cox regression analysis revealed that HABP1 $(P=0.004)$, histologic grade $(P=0.047)$, TNM stage $(P<0.001)$, Borrmann grouping $(P<0.001)$, and liver metastasis $(P=0.038)$ were independent factors for overall survival in patients with GC.

Conclusion: These findings demonstrated that HABP1 was an indicator for GC progression and poor survival, which highlighted its potential role as a therapeutic target for GCs.

Keywords: hyaluronic acid-binding protein 1, gastric cancer, overall survival rate, overexpression, prognosis

\section{Introduction}

Gastric cancer (GC) remains the fourth most frequent cancer and the second most fatal among all cancers globally. ${ }^{1,2}$ Almost two-thirds of GC cases occur in developing countries and $42 \%$ in China alone. Despite dramatic improvements in the early diagnosis and multimodal treatment of this disease, patients with advanced stage disease frequently have poor prognosis because of the high rate of metastasis. ${ }^{3}$ Over the past few decades, the prognosis of GC patients remains unsatisfactory, typically with a 5-year survival rate of $<30 \%$. ${ }^{4,5}$ Therefore, the identification of molecular prognostic biomarkers that control tumor progression and metastasis will help provide a more effective therapeutic approach to GC.

Hyaluronic acid-binding protein 1 (HABP1/gC1qR/p32), which is localized in human chromosome $17 \mathrm{p} 13.3$, is expressed ubiquitously in different rat tissues and is present in eukaryotic species from yeast to humans. ${ }^{6}$ It was first detected in human 
cervical cancer (HeLa) cells and was characterized as a novel protein with high affinity for hyaluronic acid (HA). ${ }^{7,8}$ HABP1 was reported to be overexpressed in various human cancer cell lines, such as BT549, MDA-MB-231, B16F10, and HepG2, ${ }^{9-11}$ and also in several types of human cancers, including breast cancer, ${ }^{9}$ ovarian cancer, ${ }^{12,13}$ and endometrial cancer. ${ }^{14}$ Moreover, elevated HABP1 expression has been associated with disease progression, metastasis, and poor prognosis in these cancers. ${ }^{9-14}$ However, there have been no studies examining the clinical significance of HABP1 in human GC.

The aim of this study was to determine the level of expression of HABP1 in GC and to analyze its relationship with clinicopathological features, including patient outcome.

\section{Patients and methods \\ Patients and clinical samples}

After the study was approved by the Medical Ethics Committee of the Tumor Hospital of Harbin Medical University, archived formalin-fixed, paraffin-embedded samples were collected from 181 patients with GC who were surgically treated in the Third Affiliated Hospital, Harbin Medical University, Harbin, China, between January 2009 and December 2009. In addition, 20 fresh GC and paired adjacent nonneoplastic tissues were collected and frozen at $-80^{\circ} \mathrm{C}$ until protein extraction. None of the patients received radiotherapy or chemotherapy before surgical treatment. A total of 105 patients received 3-6 cycles of oxaliplatin-based chemotherapy after surgery according to the postoperative pathological report. The staging of tumors was performed according to the American Joint Committee on Cancer criteria. ${ }^{15}$

The clinicopathological characteristics of the 181 patients with GC are listed in Table 1 . The median age was 58 years, ranging from 32 to 85 years. The follow-up period was defined as the interval between the date of diagnosis and the date of the patient's death or the last visit. All the patients with GC were followed up for survival analysis until February 28, 2015 (median, 20 months; range, 2-72 months). All patients provided written informed consent to participate in the study.

\section{Western blot analysis}

Frozen tissue specimens were homogenized in radioimmunoprecipitation assay (RIPA) buffer consisting of $1 \%$ protease inhibitor mixture. The mixture was centrifuged at $12,000 \times g$ for 15 minutes at $4^{\circ} \mathrm{C}$, and the supernatant was obtained. Total proteins were quantified, and $30 \mu \mathrm{g}$ of protein per sample was separated by $12 \%$ sodium dodecyl sulfate polyacrylamide gel electrophoresis and transferred
Table I Clinical correlation of HABPI protein expression in GC

\begin{tabular}{|c|c|c|c|c|}
\hline \multirow[t]{2}{*}{ Parameters } & \multirow{2}{*}{$\begin{array}{l}\text { Total } \\
(\mathbf{N}=\mid \mathbf{8} \mathbf{I})\end{array}$} & \multicolumn{2}{|l|}{ HABPI protein } & \multirow[t]{2}{*}{$P$-value } \\
\hline & & $\begin{array}{l}\text { Low } \\
\text { expression (\%) }\end{array}$ & $\begin{array}{l}\text { High } \\
\text { expression (\%) }\end{array}$ & \\
\hline \multicolumn{2}{|l|}{ Age (years) } & & & $0.666^{\mathrm{a}}$ \\
\hline$<60$ & 97 & $47(48.5)$ & $50(51.5)$ & \\
\hline$\geq 60$ & 84 & $38(45.2)$ & $46(54.8)$ & \\
\hline \multicolumn{2}{|l|}{ Gender } & & & $0.233^{\mathrm{a}}$ \\
\hline Male & 125 & $55(44.0)$ & $70(56.0)$ & \\
\hline Female & 56 & $30(53.6)$ & $26(46.4)$ & \\
\hline \multicolumn{2}{|c|}{ Histologic grade } & & & $0.890^{\mathrm{a}}$ \\
\hline GI/G2 & 37 & 17 (45.9) & $20(54.1)$ & \\
\hline G3 & 144 & $68(47.2)$ & $76(57.8)$ & \\
\hline \multicolumn{2}{|l|}{ TNM stage } & & & $0.006^{\mathrm{a}}$ \\
\hline I/II & 43 & $28(65.1)$ & 15 (38.9) & \\
\hline III/IV & 138 & $57(4 \mid .3)$ & $8 \mid(58.7)$ & \\
\hline \multicolumn{3}{|c|}{ Borrmann grouping } & & $0.37 I^{b}$ \\
\hline 1 & 3 & I (33.3) & $2(66.7)$ & \\
\hline II & 22 & $14(63.6)$ & $8(36.4)$ & \\
\hline III & 142 & $63(44.4)$ & $79(55.6)$ & \\
\hline IV & 14 & $7(50.0)$ & $7(50.0)$ & \\
\hline \multicolumn{3}{|c|}{ Depth of invasion } & & $0.00 \mathrm{I}^{\mathrm{a}}$ \\
\hline $\mathrm{TI} / \mathrm{T} 2$ & 23 & I8 (78.3) & $5(21.7)$ & \\
\hline $\mathrm{T} 3 / \mathrm{T} 4$ & 158 & $67(42.4)$ & 91 (57.6) & \\
\hline \multicolumn{3}{|c|}{ Lymph node metastasis } & & $0.00 \mathrm{I}^{\mathrm{a}}$ \\
\hline Negative & 33 & $24(72.7)$ & $9(27.3)$ & \\
\hline Positive & 148 & $6 I(4 \mid .2)$ & $87(58.8)$ & \\
\hline \multicolumn{3}{|c|}{ Liver metastasis } & & $0.024^{a}$ \\
\hline Negative & 160 & $80(50.0)$ & $80(50.0)$ & \\
\hline Positive & 21 & $5(23.8)$ & $16(76.2)$ & \\
\hline \multicolumn{3}{|c|}{ Peritoneum metastasis } & & $0.009^{a}$ \\
\hline Negative & 135 & 71 (52.6) & $64(47.4)$ & \\
\hline Positive & 46 & $14(30.4)$ & $32(69.6)$ & \\
\hline \multicolumn{3}{|c|}{ Tumor size (diameter), cm } & & $0.564^{\mathrm{a}}$ \\
\hline$<5$ & 60 & $30(50.0)$ & $30(50.0)$ & \\
\hline$\geq 5$ & $|2|$ & $55(45.5)$ & $66(54.5)$ & \\
\hline Location & & & & $0.423^{\mathrm{a}}$ \\
\hline Upper & 25 & $14(56.0)$ & II (44.0) & \\
\hline Middle & 45 & $18(40.0)$ & $27(60.0)$ & \\
\hline Lower & 111 & $53(47.7)$ & $58(52.3)$ & \\
\hline
\end{tabular}

Notes: aChi-square test. ' ${ }^{\text {Fisher test. }}$

Abbreviations: GC, gastric cancer; TNM, tumor, node, and metastasis.

onto polyvinylidene fluoride film (Bio-Rad, Carpinteria, $\mathrm{CA}$, USA). The membranes were blocked by $2 \%$ bovine serum albumin at $37^{\circ} \mathrm{C}$ for 1 hour and incubated with primary antibodies, anti-HABP1 (1:800 dilution, ab24733; Abcam, Cambridge, MA, USA), overnight at $4^{\circ} \mathrm{C}$. After a standard washing, the film was incubated with horseradish peroxidase-labeled secondary antibody for 1 hour at room temperature and washed again. The blots were stained using a SuperSignal Kit (Pierce, Rockford, IL, USA) and imaged by a charge-coupled camera LAS4000 (Fujifilm, Tokyo, Japan). The experiment was repeated in triplicate. 


\section{Immunohistochemistry (IHC)}

Following the manufacturer's instructions, IHC staining was performed using the Two-Step IHC Detection reagent (PV-6001) kit (Zhong Shan Golden Bridge Biological Technology Inc, Beijing, China) on formalin-fixed, paraffinembedded $4 \mu \mathrm{m}$-thick tissue sections. Briefly, the sections were immersed in 3\% hydrogen peroxide for 10 minutes to remove endogenous peroxidase. HABP1 antigen retrieval was performed by heating in a pressure cooker for 3 minutes in $10 \mathrm{mmol} / \mathrm{L}$ citrate buffer (pH 6.0). Sections were incubated with a mouse monoclonal antibody against HABP1 (1:100 dilution; ab24733) overnight at $4^{\circ} \mathrm{C}$. After washing with phosphate-buffered saline (PBS), the slides were incubated with a secondary antibody for 20 minutes at room temperature. The complexes of antigen antibody were detected with 3,3'-diaminobenzidine tetrahydrochloride (Dako, Hamburg, Germany), and the slides were lightly counterstained with hematoxylin and then examined by light microscopy. The negative control was sample stained with PBS instead of primary antibodies. Endometrial cancer with a positive HABP1 expression was used as the positive control. ${ }^{14}$

The levels of HABP1 expression were scored by combining the percentage and intensity of positively stained tumor cells. ${ }^{13,14}$ The percentage was classified as follows: $0(0 \%)$, $1(0 \%-10 \%), 2(10 \%-50 \%)$, and $3(>50 \%)$. The intensity was also scored as follows: 0 (negative staining), 1 (weak staining), 2 (moderate staining), and 3 (intense staining). The final scores of HABP 1 expression, ranging from 0 to 9 , were calculated by multiplying the positive proportion score by the staining intensity score. Patients with a final score of $<4$ were classified into low expression group and vice versa.

This procedure was carried out by two independent pathologists who were blinded to the clinicopathological variables of the patients. Any score discrepancies were reviewed by the original two pathologists and a senior pathologist until a consensus was reached.

\section{Statistical analysis}

Chi-square test or Fisher's exact test was performed to assess differences in clinicopathological parameters. Survival curves were plotted by using the Kaplan-Meier method and compared using the log-rank test. The Cox proportional hazard model was used for the multivariate analysis of the independent prognostic factors for overall survival. All of the analyses were performed using SPSS 13.0 for Windows (SPSS, Chicago, IL, USA). Two-sided $P<0.05$ was considered as statistically significant.

\section{Results}

\section{The status of HABPI protein expression in $\mathrm{GC}$ tissues}

HABP1 expression was mainly localized in the cytoplasmic compartment of the tumor cells, with minute staining in both nuclei and cytoplasm. The representative images of its immunostaining are shown in Figure 1A.

Western blot demonstrated a specific band for HABP1 at $33 \mathrm{kDa}$ (Figure 1B). Western blot analysis showed low expression in paired adjacent nonneoplastic tissues. High levels of HABP1 expression were significantly detected in GC tissues than in adjacent nonneoplastic tissues (Figure 1C, $P=0.018$ ).

\section{The association between HABPI protein expression and clinicopathological parameters in GCs}

Of the GC specimens examined (Figure 2), low HABP1 expression was detected in 85 of the 181 (47.0\%) patients and high HABP1 expression was detected in 96 of the $181(53.0 \%)$ patients. Table 1 summarizes the relationship between HABP1 expression and clinicopathological variables in GC. Elevated HABP1 expression was significantly associated with tumor, node, and metastasis (TNM) stage $(P=0.006)$, depth of invasion $(P=0.001)$, lymph node metastasis $(P=0.001)$, liver metastasis $(P=0.024)$, and peritoneum metastasis $(P=0.009)$. However, no positive correlation of HABP1 with age, gender, histologic grade, Borrmann grouping, tumor size, and location was observed $(P>0.05)$.

\section{Clinical impact of HABPI protein on survival in GCs}

Univariate combined with multivariate analyses were performed to evaluate the predictors for overall survival in GC patients (Table 2). The 5-year overall survival rate was $17.7 \%$ in patients with HABP1 overexpression and $47.2 \%(P<0.001)$ in its counterpart (Figure 3A). In addition to HABP1, histologic grade $(P=0.017)$, TNM stage $(P<0.001)$, Borrmann grouping $(P<0.001)$, depth of invasion $(P<0.001)$, lymph node metastasis $(P<0.001)$, liver metastasis $(P=0.010)$, and tumor size $(P<0.001)$ are correlated with prognosis of GC. Significant parameters in univariate Kaplan-Meier analysis were entered into the multivariate Cox regression model, and the multivariate Cox regression analysis showed that increased HABP1 expression $(P=0.004$, hazard ratio $[\mathrm{HR}]=1.730,95 \%$ confidence interval [CI]: 1.187-2.522) accompanied by histologic grade $(P=0.047, \mathrm{HR}=1.671,95 \% \mathrm{CI}: 1.007-2.773)$, TNM stage 
A
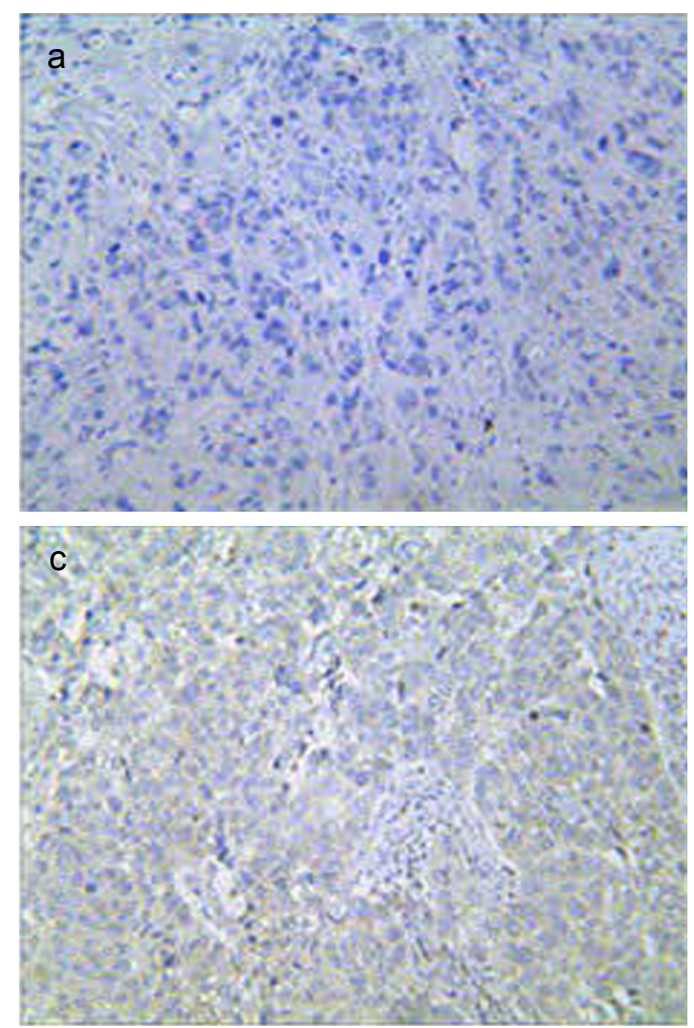
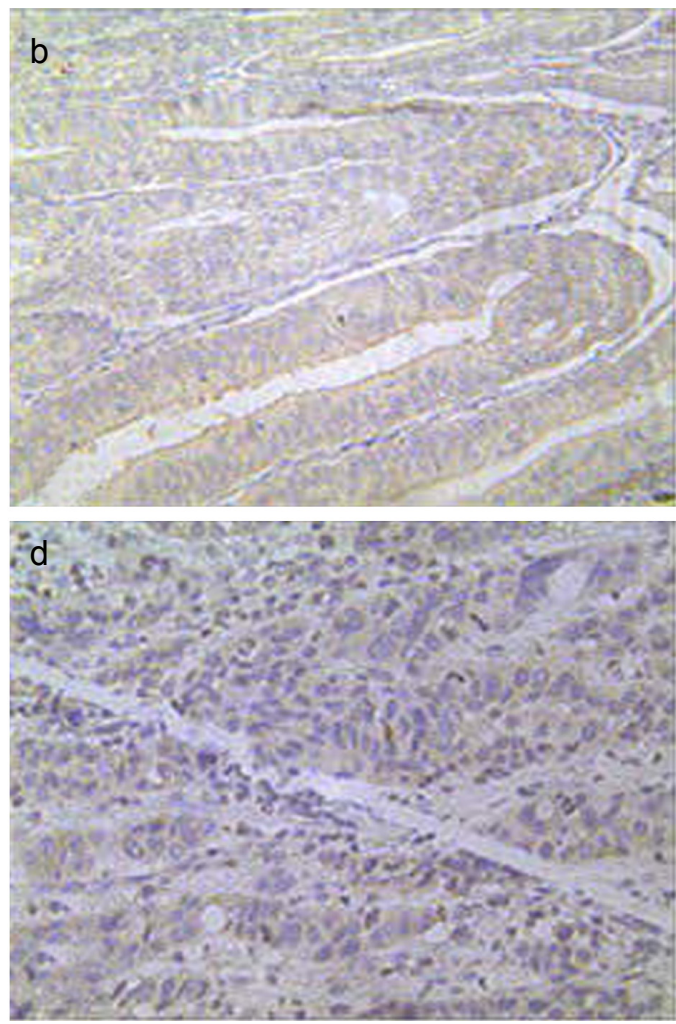

B

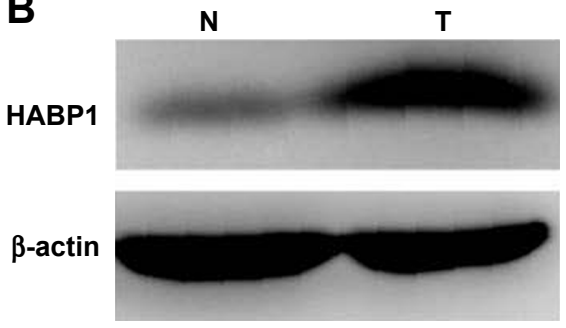

$33 \mathrm{kDa}$

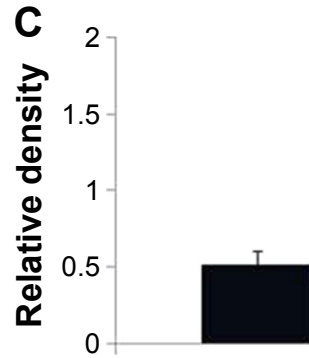

$\mathrm{N}$

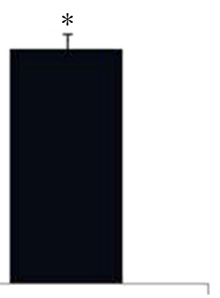

$\mathrm{T}$

Figure I The status of HABPI expression in gastric cancer tissues.

Notes: (A) Immunohistochemical staining: (a) negative control in GCs, (b) positive control in endometrial cancers, (c) low expression in GCs, and (d) high expression in GCs. (B) Western immunoblot analysis of HABPI expression in adjacent N and GC. (C) Histogram of pooled data from fresh GC tissues ( $\mathrm{n}=20$ ) and paired adjacent nonneoplastic tissues $(n=20)$. HABPI expression was obviously higher in $G C$ than that in adjacent nonneoplastic tissues $\left({ }^{*} P=0.018\right)$.

Abbreviation: GCs, gastric cancers; N, nonneoplastic tissues; T, GC tissues.

$(P<0.001, \mathrm{HR}=4.230,95 \%$ CI: 2.073-8.632), Borrmann grouping $(P=0.005, \mathrm{HR}=8.664,95 \% \mathrm{CI}: 1.890-39.719)$, and liver metastasis $(P=0.038, \mathrm{HR}=1.754,95 \% \mathrm{CI}: 1.031-2.985)$ were independent biomarkers for indicating overall survival in patients with GC.

To eliminate the effect of TNM stage on prognosis, we performed a stage-stratified analysis of all patients according to the level of HABP1 expression and found that elevated HABP1 expression highly affected overall survival in patients with both TNM stage I/II $(P=0.002)$ and TNM stage III/IV $(P=0.038)$. The survival curves for the patients with GC in the two groups stratified by TNM stage are specified in Figure 3B and C.

\section{Discussion}

In this study, we have demonstrated that HABP1 protein expression in GC tissues was strongly higher than that in adjacent nonneoplastic tissues. Elevated HABP1 expression was highly associated with TNM stage, depth of invasion, lymph node metastasis, liver metastasis, peritoneum metastasis, and poor prognosis, suggesting that HABP1 protein could be a valuable biomarker to indicate tumor progression and prognosis for patients with GC.

HABP1 has been reported to appear in various cellular compartments, including the nucleus, ${ }^{16}$ mitochondria, ${ }^{17,18}$ and Golgi, ${ }^{19}$ and secreted into the extracellular ${ }^{20}$ in different 

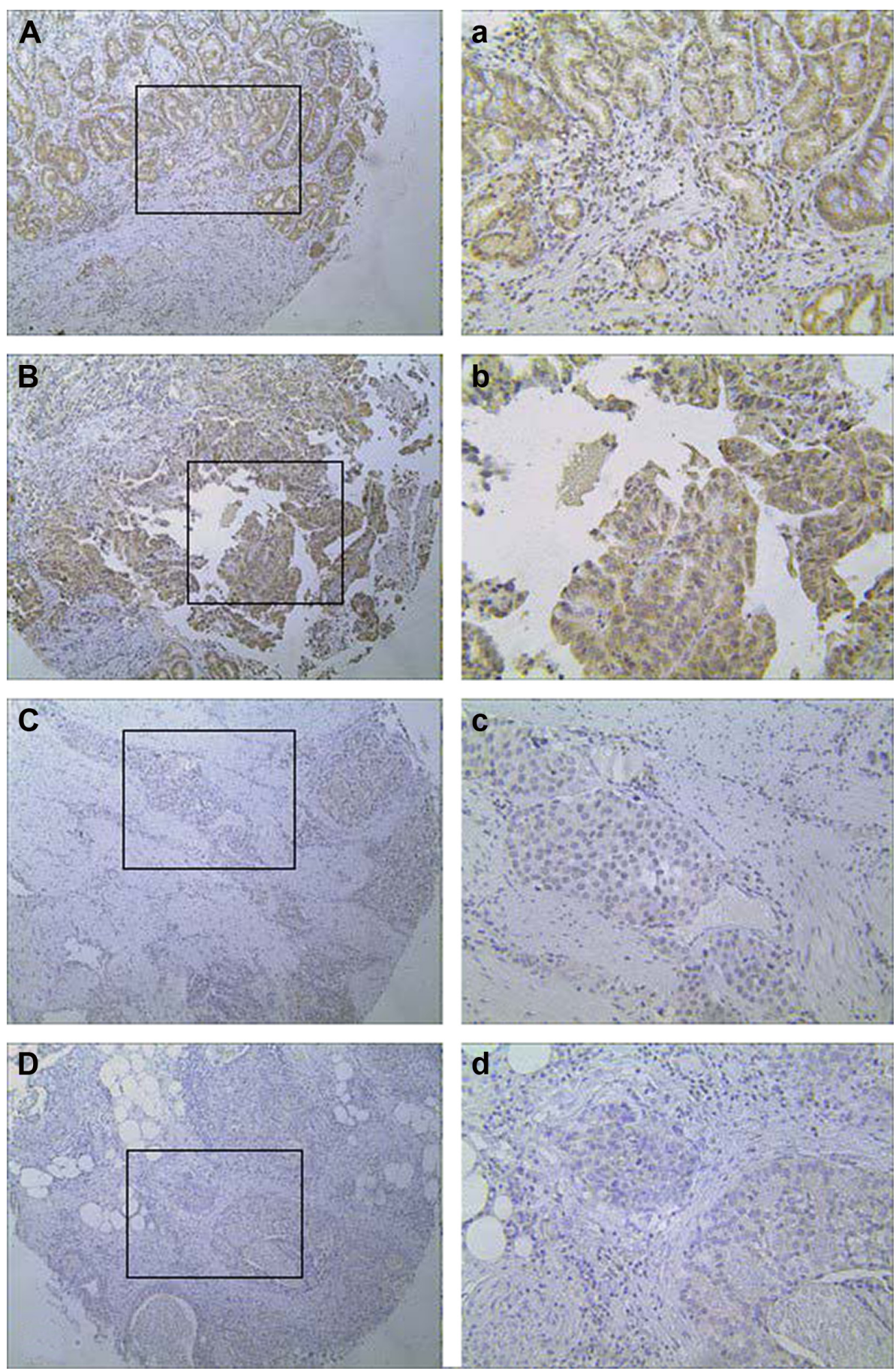

Figure 2 Representative immunostaining for HABPI expression in GC.

Notes: (A, a and B, b) High expression in GC. (C, c and D, d) Low expression in GC. (A-D) Original magnification: $\times 100$. Images a-d show the magnification $(\times 200)$ of images A-D.

Abbreviation: GC, gastric cancer.

cell types. However, we only observed minute HABP1 staining in nuclei and predominate HABP1 staining in cytoplasm. Upon the observation that the nuclear translocation of HABP1 is concurrent with that of ERK, it indicates that ERK activation is a requirement for the translocation of HABP $1 .{ }^{21}$ This may attribute to the different cell cycles, different cell types, and the specific stages of tumor progression. $^{22}$

Our results are similar to those of previous studies on the potential function of increased HABP1 expression in carcinogenesis, progression, invasion, and metastasis in malignant tumors. ${ }^{9,10,13,14}$ Increased HABP1 expression in endometrial 
Table 2 Univariate and multivariate survival analyses of overall survival in 181 patients with GC

\begin{tabular}{|c|c|c|c|c|}
\hline \multirow[t]{3}{*}{ Parameters } & \multicolumn{4}{|l|}{ Overall survival } \\
\hline & \multicolumn{2}{|l|}{ Univariate } & \multicolumn{2}{|l|}{ Multivariate } \\
\hline & $\begin{array}{l}\text { Mean } \pm \text { standard } \\
\text { error (months) }\end{array}$ & $P$-value ${ }^{a}$ & HR (95\% Cl) & $P$-value ${ }^{b}$ \\
\hline Age (years) & & 0.412 & & \\
\hline$<60$ & $36.1 \pm 2.8$ & & & \\
\hline$\geq 60$ & $31.9 \pm 2.8$ & & & \\
\hline Gender & & 0.601 & & \\
\hline Male & $33.9 \pm 2.4$ & & & \\
\hline Female & $35.1 \pm 3.7$ & & & \\
\hline Histologic grade & & 0.017 & & 0.047 \\
\hline GI/G2 & $41.4 \pm 4.3$ & & 1.000 (reference) & \\
\hline G3 & $30.0 \pm 2.2$ & & I.67I (1.007-2.773) & \\
\hline TNM stage & & $<0.001$ & & $<0.001$ \\
\hline I/II & $61.8 \pm 3.2$ & & 1.000 (reference) & \\
\hline III/IV & $25.9 \pm 1.9$ & & $4.230(2.073-8.632)$ & \\
\hline Borrmann grouping & & $<0.00 \mathrm{I}$ & & $<0.001$ \\
\hline I & $28.3 \pm 13.7$ & & I.000 (reference) & \\
\hline II & $56.7 \pm 4.8$ & & $0.784(0.152-4.053)$ & 0.772 \\
\hline III & $33.4 \pm 2.2$ & & $1.612(0.394-6.597)$ & 0.506 \\
\hline IV & $7.9 \pm 0.9$ & & $8.664(1.890-39.719)$ & 0.005 \\
\hline Depth of invasion & & $<0.00 \mathrm{I}$ & & \\
\hline $\mathrm{TI} / \mathrm{T} 2$ & $63.3 \pm 4.1$ & & & \\
\hline $\mathrm{T} 3 / \mathrm{T} 4$ & $30.2 \pm 2.0$ & & & \\
\hline Lymph node metastasis & & $<0.001$ & & \\
\hline Negative & $56.6 \pm 3.9$ & & & \\
\hline Positive & $29.3 \pm 2.1$ & & & \\
\hline Liver metastasis & & 0.010 & & 0.038 \\
\hline Negative & $36.1 \pm 2.2$ & & 1.000 (reference) & \\
\hline Positive & $20.9 \pm 4.4$ & & $1.754(1.031-2.985)$ & \\
\hline Peritoneum metastasis & & 0.376 & & \\
\hline Negative & $34.9 \pm 2.4$ & & & \\
\hline Positive & $32.6 \pm 3.7$ & & & \\
\hline Tumor size (diameter), $\mathrm{cm}$ & & $<0.001$ & & \\
\hline$<5$ & $49.5 \pm 3.4$ & & & \\
\hline$\geq 5$ & $26.9 \pm 2.2$ & & & \\
\hline Location & & 0.589 & & \\
\hline Upper & $36.9 \pm 5.5$ & & & \\
\hline Middle & $29.9 \pm 3.9$ & & & \\
\hline Lower & $35.6 \pm 2.6$ & & & \\
\hline HABPI expression & & $<0.001$ & & 0.004 \\
\hline Low & $42.8 \pm 3.1$ & & 1.000 (reference) & \\
\hline High & $26.9 \pm 2.4$ & & $1.730(1.187-2.522)$ & \\
\hline
\end{tabular}

Notes: a Log-rank test. ${ }^{\circ}$ Cox regression test.

Abbreviations: $\mathrm{Cl}$, confidence interval; $\mathrm{HR}$, hazard ratio; TNM, tumor, node, and metastasis.

cancer correlated with Federation International of Gynecology and Obstetrics (FIGO) stage, histological grade, depth of myometrial invasion, vascular/lymphatic invasion, and lymph node metastasis..$^{14}$ Furthermore, HABP1 was overexpressed in breast cancer and correlated with tumor stage and lymph node metastasis. ${ }^{9}$ In addition to the abovementioned results, HABP1 was associated with histological grade, tumor size, and recurrence in triple-negative breast cancer. ${ }^{23}$ Also, $\mathrm{HABP} 1$ was reported to relate with histological grade, serum
CA125, and FIGO stage in ovarian cancer. ${ }^{12}$ Collectively, the above data suggest that HABP1 plays an important role in the oncogenesis and progression of human tumors.

Recently, studies have shown that HABP1 could be implicated in tumor growth, proliferation, migration, and metastasis; however, the definite mechanism remains unclear. Prakash et $\mathrm{a}^{10}$ found that HABP1 involved in tumor formation with the research that the treatment of curcumin, the anticancer drug along with HABP1, could inhibit the migration, expression 

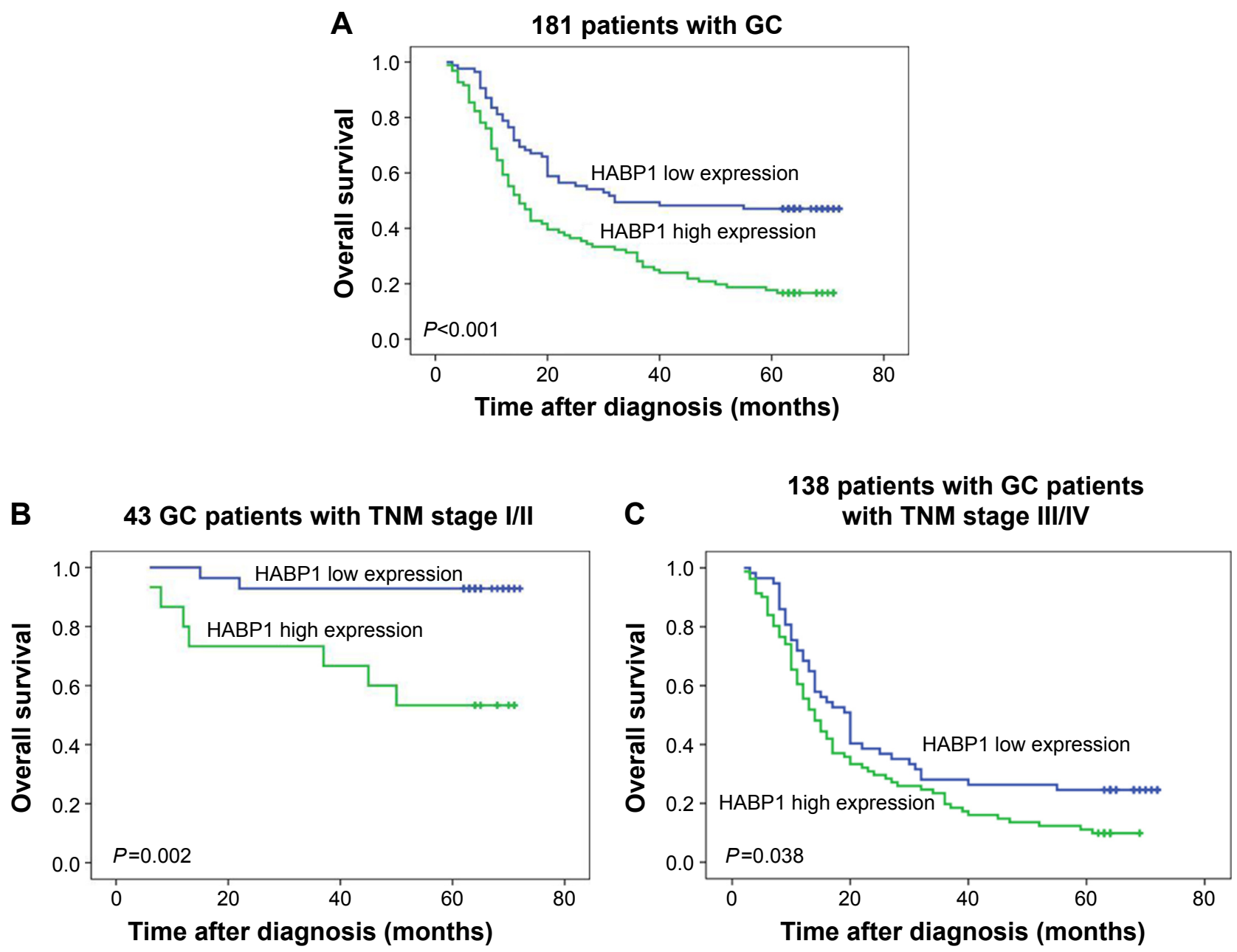

Figure 3 Kaplan-Meier analysis of HABPI expression in patients with GC.

Notes: (A) The relationship of HABPI expression with overall survival in all I8I patients. (B) The relationship of HABPI expression with overall survival in TNM stage I/II. (C) The relationship of HABPI expression with overall survival in TNM stage III/IV. Abbreviations: GC, gastric cancer; TNM, tumor, node, and metastasis.

of MT1-MMP, and activation of MMP-2. Another research observed that with the onset of metastasis, HABP1 overexpression was confined to metastatic islands, while it disappeared gradually from the surrounding mass, implying a role in the regulation of tumor metastasis. ${ }^{22}$ In HepG2 cells, constitutively increased HABP1 expression leads to enhanced tumorigenic potential by HA-mediated pathways. ${ }^{11}$ Saha et $\mathrm{al}^{24}$ demonstrated that HABP1 induced HA cable formation in enhancing tumor potency by maintaining the oxidant levels and subsequent autophagic vacuolation. Silencing HABP1 inhibits proliferation and suppresses the migration and invasion ability of BT549 and MDA-MB-231 cell lines and also obviously slows down tumor growth in mice. ${ }^{9}$ All these results indicate the possibility to make HABP1 as a potential therapy target for GC. Definitely, further evidence from basic study is still needed. Besides, because of mitochondrial accumulation of HABP1, excess reactive oxygen species (ROS) generation in HABP1-overexpressing cells could lead to apoptosis in fibroblasts. ${ }^{25}$ Yet, whether HABP1 was associated with apoptosis in tumor cells especially chemotherapy resistance remains to be elucidated.

\section{Conclusion}

HABP1 expression is elevated in some GCs. High HABP1 expression correlates clearly with disease progression, metastasis, and poor survival. Therefore, the HABP1 gene is an important biomarker for predicting unfavorable biological behavior and a potential therapy target for GC.

\section{Acknowledgments}

We thank all the people who had participated in this study, especially Qi Huang for technical assistance and Tianbo Liu for statistical analysis.

\section{Disclosure}

The authors report no conflicts of interest in this work. 


\section{References}

1. May M. Statistics: attacking an epidemic. Nature. 2014;509:S50-S51.

2. Jemal A, Bray F, Center MM, Ferlay J, Ward E, Forman D. Global cancer statistics. CA Cancer J Clin. 2011;61(2):69-90.

3. Shah MA, Ajani JA. Gastric cancer: an enigmatic and heterogeneous disease. JAMA. 2010;303(17):1753-1754.

4. Ilson DH. Angiogenesis in gastric cancer: hitting the target? Lancet. 2014;383(9911):4-6.

5. Oba K, Paoletti X, Alberts S, et al. Disease-free survival as a surrogate for overall survival in adjuvant trials of gastric cancer: a meta-analysis. J Natl Cancer Inst. 2013;105(21):1600-1607.

6. Majumdar M, Bharadwaj A, Ghosh I, Ramachandran S, Datta K. Evidence for the presence of HABP1 pseudogene in multiple locations of mammalian genome. DNA Cell Biol. 2002;21(10):727-735.

7. Gupta S, Batchu RB, Datta K. Purification, partial characterization of rat kidney hyaluronic acid binding protein and its localization on the cell surface. Eur J Cell Biol. 1991;56(1):58-67.

8. Krainer AR, Mayeda A, Kozak D, Binns G. Functional expression of cloned human splicing factor SF2: homology to RNA-binding proteins, U1 70K, and Drosophila splicing regulators. Cell. 1991;66(2): 383-394.

9. Niu M, Sun S, Zhang G, Zhao Y, Pang D, Chen Y. Elevated expression of HABP1 is correlated with metastasis and poor survival in breast cancer patients. Am J Cancer Res. 2015;5(3):1190.eCollection1198.eCollection.

10. Prakash M, Kale S, Ghosh I, Kundu GC, Datta K. Hyaluronan-binding protein 1 ( $\mathrm{HABP} 1 / \mathrm{p} 32 / \mathrm{gC} 1 \mathrm{qR})$ induces melanoma cell migration and tumor growth by NF-kappa B dependent MMP-2 activation through integrin $\alpha(v) \beta(3)$ interaction. Cell Signal. 2011;23(10):1563-1577.

11. Kaul R, Saha P, Saradhi M, et al. Overexpression of hyaluronanbinding protein 1 (HABP1/p32/gC1qR) in HepG2 cells leads to increased hyaluronan synthesis and cell proliferation by up-regulation of cyclin D1 in AKT-dependent pathway. J Biol Chem. 2012;287(23): 19750-19764.

12. Yu G, Wang J. Significance of hyaluronan binding protein (HABP1/ $\mathrm{P} 32 / \mathrm{gC} 1 \mathrm{qR})$ expression in advanced serous ovarian cancer patients. Exp Mol Pathol. 2013;94(1):210-215.

13. Yu H, Liu Q, Xin T, et al. Elevated expression of hyaluronic acid binding protein 1 (HABP1)/P32/C1QBP is a novel indicator for lymph node and peritoneal metastasis of epithelial ovarian cancer patients. Tumour Biol. 2013;34(6):3981-3987.
14. Zhao J, Liu T, Yu G, Wang J. Overexpression of HABP1 correlated with clinicopathological characteristics and unfavorable prognosis in endometrial cancer. Tumour Biol. 2015;36(2):1299-1306.

15. Sobin L, Gospodarowicz M, Wittekind C, editors. TNM Classification of Malignant Tumours (UICC International Union Against Cancer). 7th ed. New York: Wiley-Blackwell; 2009.

16. Brokstad KA, Kalland KH, Russell WC, Matthews DA. Mitochondrial protein p32 can accumulate in the nucleus. Biochem Biophys Res Commun. 2001;281(5):1161-1169.

17. Muta T, Kang D, Kitajima S, Fujiwara T, Hamasaki N. p32 protein, a splicing factor 2-associated protein, is localized in mitochondrial matrix and is functionally important in maintaining oxidative phosphorylation. J Biol Chem. 1997;272(39):24363-24370.

18. McGee AM, Baines CP. Complement 1q-binding protein inhibits the mitochondrial permeability transition pore and protects against oxidative stress-induced death. Biochem J. 2011;433(1):119-125.

19. Sengupta A, Banerjee B, Tyagi RK, Datta K. Golgi localization and dynamics of hyaluronan binding protein 1 (HABP1/p32/C1QBP) during the cell cycle. Cell Res. 2005;15(3):183-186.

20. Lim BL, Reid KB, Ghebrehiwet B, Peerschke EI, Leigh LA, Preissner KT. The binding protein for globular heads of complement $\mathrm{C} 1 \mathrm{q}, \mathrm{gC} 1 \mathrm{qR}$. Functional expression and characterization as a novel vitronectin binding factor. J Biol Chem. 1996;271(43):26739-26744.

21. Majumdar M, Meenakshi J, Goswami SK, Datta K. Hyaluronan binding protein $1(\mathrm{HABP} 1) / \mathrm{C} 1 \mathrm{QBP} / \mathrm{p} 32$ is an endogenous substrate for MAP kinase and is translocated to the nucleus upon mitogenic stimulation. Biochem Biophys Res Commun. 2002;291(4):829-837.

22. Ghosh I, Chowdhury AR, Rajeswari MR, Datta K. Differential expression of hyaluronic acid binding protein 1 (HABP1)/P32/C1QBP during progression of epidermal carcinoma. Mol Cell Biochem. 2004;267(1-2): 133-139.

23. Wang J, Song Y, Liu T, et al. Elevated expression of HABP1 is a novel prognostic indicator in triple-negative breast cancers. Tumour Biol. 2015;36(6):4793-4799.

24. Saha P, Ghosh I, Datta K. Increased hyaluronan levels in HABP1/p32/ gC1qR overexpressing HepG2 cells inhibit autophagic vacuolation regulating tumor potency. PLoS One. 2014;9(7):e103208.

25. Chowdhury AR, Ghosh I, Datta K. Excessive reactive oxygen species induces apoptosis in fibroblasts: role of mitochondrially accumulated hyaluronic acid binding protein 1 (HABP1/p32/gC1qR). Exp Cell Res. 2008;314(3):651-667.
OncoTargets and Therapy

\section{Publish your work in this journal}

OncoTargets and Therapy is an international, peer-reviewed, open access journal focusing on the pathological basis of all cancers, potential targets for therapy and treatment protocols employed to improve the management of cancer patients. The journal also focuses on the impact of management programs and new therapeutic agents and protocols on
Dovepress

patient perspectives such as quality of life, adherence and satisfaction. The manuscript management system is completely online and includes a very quick and fair peer-review system, which is all easy to use. Visit http://www.dovepress.com/testimonials.php to read real quotes from published authors. 